\title{
CHARACTERIZATION OF PUTATIVE HEAT SHOCK TRANSCRIPTION FACTOR $(H s f 2)$ GENE INVOLVED IN REGULATING THE EXPRESSION OF HSP90 IN WHEAT UNDER TERMINAL HEAT STRESS
}

\author{
Kavita Dubey* ${ }^{*}$, Suneha Goswami ${ }^{1}$, Narendra Kumar ${ }^{2}$, Ranjeet R. Kumar*1, Shelly Praveen ${ }^{1}$
}

${ }^{1}$ Division of Biochemistry, IARI, PUSA Campus, New Delhi - 110 012, India

${ }^{2}$ IMS Engineering College, Ghaziabad, Uttar Pradesh -201009, India

Received - September 28, 2020; Revision - November 25, 2020; Accepted - December 24, 2020

Available Online - December 30, 2020

DOI: http://dx.doi.org/10.18006/2020.8(6).765.773

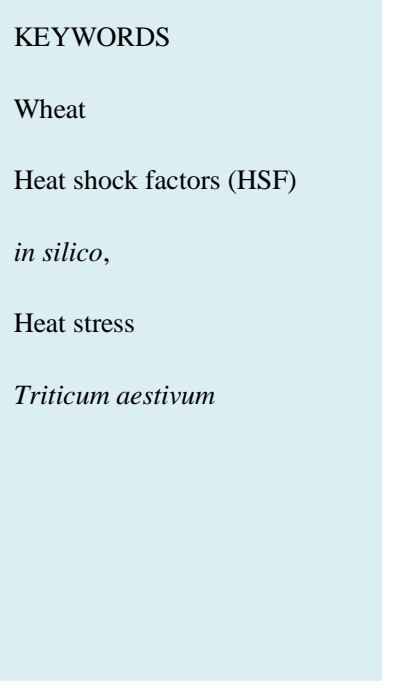

\begin{abstract}
Wheat, being staple food grain crop, is highly sensitive to heat stress. The effect is more evident under present threat of global climate change. Very limited information about heat-responsive transcription factor is known in wheat. A putative Heat Shock Factor (HSF) was cloned from wheat under HS. The gene was titled as Hsf2 (acc No. KP063542). The nucleotide sequence was found to be 1551 bp long with open reading frame (ORF) of $1125 \mathrm{bp}$ (5'UTR of 213bp and 3'UTR of 213bp). The amino acid sequence showed the presence of HSF_ DNA binding domain having high degree of similarity (homology) with other HSF coding gene of related species (Aegilops tauschii with 95\% homology and 100\% homology with Chinese spring cultivar of Triticum aestivum). The protein was observed to be localized in the nucleus. Phosphorylation study showed the presence of phosphorylated threonine at seventeen sites in amino acid sequence. Expression analysis of $H s f 2$ showed maximum relative fold expression (2.04fold) in the leaves of HD2967 under HS, as compared to control. The transcript abundance was observed maximum in thermotolerant $c v$., as compared to thermo susceptible. Current study established positive correlation between the expression of Hsf2 and HSP90 under HS. Hsf2, being regulator of HSPs can be used as potential molecular marker for screening wheat germplasm for thermo tolerance. It will pave the way for the development of 'climate-smart' wheat crop.
\end{abstract}

* Corresponding author

E-mail: dubeykavita786@gmail.com (Kavita Dubey); ranjeetranjaniari@gmail.com (RanjeetRanjan Kumar)

Peer review under responsibility of Journal of Experimental Biology and Agricultural Sciences.

Production and Hosting by Horizon Publisher India [HPI] (http://www.horizonpublisherindia.in/).

All rights reserved.
All the articles published by Journal of Experimental Biology and Agricultural Sciences are licensed under a Creative Commons Attribution-NonCommercial 4.0 International License Based on a work at www.jebas.org.

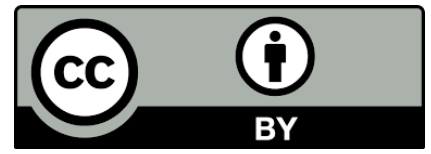




\section{Introduction}

Wheat is among the three largest staple crops all over the world. A major population of the world considers wheat as the main cereal. It is called the "King of cereals" for its high potential for productivity and cultivation capability over a huge area. Important members of the genus Triticum are the hexaploid species Triticum aestivum L., (bread wheat) and tetraploid species are T. durum, T. Dicoccum and $T$. Monococcum is cultivated all over the world (Willenborg \& Van Acker, 2008). The crop contains 12.1 percent protein, 1.8 percent lipids, 1.8 percent ash, 2.0 percent reducing sugar, 6.7 percent pentosans, 59.2 percent starch, 70 percent total carbohydrates, as collected under the nutritional profiling, providing $314 \mathrm{~K} \mathrm{cal} / 100 \mathrm{~g}$ of food (Aastha et al., 2019). Wheat is eminent source of vitamins and minerals with $\mathrm{Ca}(37 \mathrm{mg} / 100$ $\mathrm{g}), \mathrm{Fe}(4.1 \mathrm{mg} / 100 \mathrm{~g})$, vitamin B1 $(0.45 \mathrm{mg} / 100 \mathrm{~g})$, Vitamin B2 $(0.13 \mathrm{mg} / 100 \mathrm{~g})$ and nicotinic acid $(5.4 \mathrm{mg} / 100 \mathrm{mg})$ (Rosell., 2012).

The climate changes have affected the production of wheat quite adversely and this has been prominent over the decade. As a result of the climatic variations, an adverse effect on wheat has been observed due to both biotic and abiotic stresses. High temperature stress, is one of the prominent abiotic stresses, which influences development and yield of wheat during the stages of pollination and grain-filling. Wheat has different toleration levels to heat stresses during diverse phenological phases, but during reproductive stage, the heat stress is more harmful as compared to vegetative stage as a result of the straight impact on the grain number and dry weight (Rezaei et al., 2018).

The ability to bring changes in membrane fluidity, metabolism disturbance, protein confirmation and cytoskeleton assembly, increases adaptation to surrounding temperature in all plants (Ruelland \& Zachowski, 2010).The series of responses stimulates adaptable forms including expression of heat shock proteins, until optimum cellular equilibrium comes. The higher temperature level than the optimum causes irreversible damage resulting in 'heat stress' which is detrimental to crop development and growth (Wahid et al., 2007).

The interval and level of HS poorly disturbs the protein metabolism, hinders protein accumulation, and induction of certain protein synthesis (Monjardino et al., 2005; Castro et al., 2007). Wheat adapts to the environmental changes by triggering the defense mechanisms at biochemical and molecular level. At molecular level, it leads to the overexpression of stress-associated genes like HSPs, antioxidant enzyme genes, signalling molecules, etc. (Kumar \& Rai, 2014). HSPs protect proteins from heat-initiated accumulation and in this manner over the reclamation period, facilitate their recollapsing (Maestri et al., 2002) Expression of HSP is a principal reaction to heat stress (Rampino et al., 2009). When exposed to HS $\left(>35^{\circ} \mathrm{C}\right)$, typical protein unification in wheat is decreased, yet HSPs are expressed (Skylas et al., 2002).

There are many reports which evidences that, expressions of HSPs are mainly regulated by HSFs under heat (Scharf et al., 2012). These transcription factors are considered to be the terminal component of signal transduction pathway that are responsible for expression of genes involved in abiotic stresses (Nover et al., 2001). During the growth and development stages, the HSFs play a key role in stress response. It has been reported that, there is positive correlation in the expression of HSPs (HSP70 and HSP17) with expression of HSFs (HSF3 and HSFA4a) at $42^{\circ} \mathrm{C}$ HS wheat for 2 hours (Kumar et al., 2013). In response to heat stress, HSP60 and HSP70 emerged as the exceedingly well-maintained proteins in nature, and plays a major role in heat stress tolerance (Kills, 2003). There are reports on synergistic action of different HSFs. In order to identify the expression of heat-responsive genes via heat shock factors (HSFs), plants have their own set of parameters. The HSFs preserve protein folding homeostasis and take the degree of tolerance under thermal stress.

In case of wheat some of the HSFs is being reported and characterized, thus we have recognised and cloned a putative heat-responsive transcription factor $(H s f 2)$ gene from $T$. aestivum and characterize the relationship with its target (HSP90) under HS (Heat stress).

\section{Materials and Methods}

\subsection{Plant material}

In the current study, two wheat cultivars - HD2329 (thermosusceptible) and HD2967 (thermotolerant) were used. The seeds of both the cultivars were pre-soaked in $0.5 \%$ Bavistin and then sown in twenty-four pots (for each variety, twelve) having equivalent quantity of perlite to farm yard manure (FYM) mixture. Plants were permitted to grow under ideal conditions in a growth chamber $\left(22 \pm 3^{\circ} \mathrm{C}, 75\right.$ percent relative humidity and $250 \mu \mathrm{mol} \mathrm{m}-1 \mathrm{~s}-1 \mathrm{PAR})$ in the $16 \mathrm{~h} /$ light/8h dark period in the National Phytotron Facility, IARI, New Delhi. Plants (three pots from each variety) were given heat stress at $42^{\circ} \mathrm{C}$ for $2 \mathrm{~h}$ at pollination and grain-filling stages; a control in triplicate was kept at $22 \pm 3^{\circ} \mathrm{C}$ for each stage and the leaf samples were collected based on the Feekes scale. The heat stress treatment was in accordance to the method described by Kumar et al. (2019). In order to validate the $H s f 2$ TF gene, seedlings of wheat $c v$. HD2967 and HD2329 were used for the analysis. The 15 days old seedlings were given HS 
at $42^{\circ} \mathrm{C}$ for $2 \mathrm{~h}$, and the samples were collected in triplicates for further downstream application. One set kept at $\left(22 \pm 3^{\circ} \mathrm{C}\right)$ was used as control.

A separate experiment was conducted for differential expression analysis of $H s f 2\left(30^{\circ} \mathrm{C}\right.$ and $38^{\circ} \mathrm{C}$ for $\left.2 \mathrm{hr}\right)$ at pollination as well as grain filling stage in thermotolerant (HD2985, HD2967) and thermo susceptible (HD2329) wheat cultivars for comparing the expression. The pre-treated seeds were sown in thirty-six pots (twelve pots for each variety) and allowed to grow as mentioned above. Plants (six pots in a set of three for each variety) were exposed to heat stress at $30^{\circ} \mathrm{C}$ and $38^{\circ} \mathrm{C}$ for $2 \mathrm{hr}$ at pollination and grain filling stage. The control in triplicate was kept at $22 \pm 3^{\circ} \mathrm{C}$ for each stage and the leaf samples were collected based on the feekes scale.

\subsection{Total RNA Isolation and cDNA Synthesis}

The complete RNA was isolated from $100 \mathrm{mg}$ of stored plant tissue utilizing TriZol reagent (Invitrogen, Carlsbad, CA, USA) according to manufacturer's instruction manual. Using the Trizol process (Invitrogen, UK), complete RNA was extracted from collected plant tissues. Isolated RNA consistency has been evaluated on 1.2\% Formaldehyde MOPS agarose gel by electrophoresis. The Complementary DNA (cDNA) was synthesised by means of the Revert Aid H Minus First stand cDNA synthesis kit (Fermentas, Thermo Fisher Scientific, USA) as per the protocol of manufacturer.

\subsection{Cloning and expression analysis of $\mathrm{Hsf} 2$}

The cDNA synthesised from seedling of HD2967 cv. was used for PCR amplification of $H s f 2$ gene by using forward primer (Fp-5'-CAAACTGCTACAGCGGGAGT-3' ${ }^{\prime} \mathrm{Tm}-60.45^{\circ} \mathrm{C}$ ) and reverse primer (Rp-5'TACGGTACCAATCCCCTCAA 3'; Tm$60.18^{\circ} \mathrm{C}$ ). In pGEMT Easy vector (Promega) we cloned the amplified product and sequenced using M13 forward and reverses primers.
For expression analysis the primers were designed from $H s f 2$ (Acc. no. KP063542) and HSP90 (Acc. no. JN052206). The cDNA of both control and Heat Stress $\left(42^{\circ} \mathrm{C}, 2 \mathrm{hr}\right)$ treated leaf samples of HD2329 and HD2967 $c v$. of wheat at pollination and grain filling stage were subjected to qRT-PCR using KAPA SYBR Green qPCR master mix on the CFX96 real-time PCR platform (BioRad, UK) and $\beta$-actin gene (Acc. no. AF282634) was used as endogenous control for normalizing the $\mathrm{Ct}$ value. Comparative expressions of genes were computed using the $2-\Delta \Delta \mathrm{Ct}$ process. The primers used for expression analysis are displayed in Table $\mathbf{1 .}$

\subsection{Characterization of identified $\mathrm{Hsf2}$ using in silico tools}

BLASTn (https://blast.ncbi.nlm.nih.gov) was employed for performing the homology search of TaHsf sequence. NCBI tool was used for constructing phylogenetic tree based on nucleotide sequence. SWISS-modeller with Automated Mode (Arnold et al., 2006) was used for predicting the 3D structure. Different estimation patterns under protein structure and the archetypal evaluation tools at Swiss-model server were used to subject the modelled structure for validation and assessments. It was validated using Anoleaplot and Qmean (Benkert et al., 2009) for the packaging quality; while the analysis of the stereochemical and the overall quality of the structure was performed using PROCHECK (Ramachandran plot). The domain and family analysis of amino acid sequence was done using CDD tool (Conserved Domain Database) from NCBI (http:// www.ncbi. nlm.nih.gov/cdd). The physiochemical characterization of $\mathrm{Hsf}$ was computed using the Expasy Protparam tool (http://web.expasy.org/protparam/).

The protein-protein interaction study was performed using STRING database. The phosphorylation site detection was done using NetPhos.3.1 tool. The inter-cellular localization of the $H s f 2$ was predicted using PSORT software (http://psort.hgc.jp)

Table1 List of primers used for quantitative real time expression analysis of $H s f 2$

\begin{tabular}{|ccc|}
\hline Gene & Forward Primer & $\mathrm{Tm}^{\circ} \mathrm{C}$ \\
\hline qHSf2-Fp & AAAGCGGCTGCTTTGTGA & 63.4 \\
\hline qHsf2-Rp & TCCGGCACAATCTTCCTA & 60.4 \\
\hline qHsp90-Fp & TGATGATGGGTGGACTGCCAACAT & 62.7 \\
\hline qHsp90-Rp & TCTCGAAGAGCAGCATCACAAGGT & 62.7 \\
\hline q $\beta$-Actin-Fp & GCGGTCGAACAACTGGTATT & 63.7 \\
\hline q $\beta$-Actin-Rp & GGTCCAAACGAAGGATAGCA & 63.8 \\
\hline
\end{tabular}

Journal of Experimental Biology and Agricultural Sciences http://www.jebas.org 


\section{Results}

3.1 Sequence identification of cloned Hsf and expression analysis using qRT PCR

The ampliconso obtained after RT-PCR has size of $1.5 \mathrm{~kb}$ and cloning in pGEMTEasy was confirmed by EcoRI restriction (Figure 1). The cloned gene was sequenced by Sanger's dideoxy method and submitted in NCBI GenBank with Accession number KP063542. Hsf2 gene was 1551 nucleotide long with 5 'UTR region of $213 \mathrm{bp}$ and 3 'UTR region of $213 \mathrm{bp}$. The gene ORF codes for 374 amino acids.

The comparative expression analysis of $H s f 2$ in leaf samples of wheat $c v$. HD2985 (Thermotolerant) and HD2329 (thermo susceptible) under heat stress $\left(42^{\circ} \mathrm{C}, 2 \mathrm{hr}\right)$ showed expression of 1.91fold in HD2967 and 1.41 fold in HD2329 at pollination and 2.04 fold and 1.61 fold respectively at grain filling stage (Figure 2a-b). The expression analysis under differential heat stress $\left(30^{\circ} \mathrm{C}\right.$ and $38^{\circ} \mathrm{C}$ for $\left.1 \mathrm{hr}\right)$ showed that the expression of HSP90increases with increase in temperature at pollination and grain filling stages. Among the cultivars, thermo-tolerant wheat cv. HD2985 and HD2967 had better expression of HSP90, as compared to the thermo-susceptible cv. HD2329 (Figure 3a-b).

\subsection{In silico characterization of $H s f 2$}

Phylogenetic data indicates that TaHsf has the highest identity of the sequence and similarity to heat sock transcription factors of Aegilops tauschii and Chinese spring cultivar of Triticum aestivum (Figure 4). The presence of the domain for heat shock binding in the sequence obtained after Multiple ClustalW alignment shows similarity with the HSF domain existing in other heat-responsive TFs described from closely related species.

The Protein Assembly and Valuation Tools at Swiss Model server (https://swissmodel.expasy.org/) were used to evaluate the generated structure. The GMQE and QMEAN6 scores of 0.17 and -0.63 respectively were predicted for the selected model (Figure 5). The conserved domain was predicted using NCBI's CD search tool which revealed the existence of HSF_DNA bind domain and thus proves that Hsf2 is a transcription factor (Figure 6). A depiction of $86.7 \%$ in the favourable regions was done by PROCHECK (Ramachandran Plot) and it was above the optimal score (Figure 7). A significant information about the nature and composition of the protein was provided by the physio-chemical parameter predicted by ExPASyProtParam tool (http://web.expasy.org/protparam/), number of amino acids: 374, molecular weight: 40449.01 . The majority of the protein portion is occupied by means of aromatic amino acids as indicated by the higher value of the extinction coefficient (Ext. coefficient 35785), whereas, the instability of protein could be significantly deduced from the value of Instability Index (52.53) which is greater than 40. Also, the protein is thermo stable as the aliphatic index (Aliphatic Index: 65.29) is higher. The protein is proven to be hydrophilic and soluble considering the negative value of GRAVY (-0.552), which is the estimate value for the solubility of proteins. PPI enrichment p-value is 0.718 (Figure 8) shows the Protein-Protein Hsf2 network interaction established by the STRING database based on the spring model. The phosphorylation site detection using NetPhos.3.1 implied that mostly threonine (17 sites $)$ in sequence were above threshold of phosphorylation potential which might favour the potential of Hsf2 TF in folding of protein and chaperonic activity under high temperatures (Figure 9)

\section{Discussion}

The genes of heat shock factor (HSF) family play a vital role in regulating the functions of stress associated genes (SAGs) during heat stress tolerance (Pei et al., 2020). The analysis of HSF genes in model plants like Arabidopsis, rice etc. has being carried out extensively. Heat shock transcription factors (Hsfs) carries out a core administrative role in thermo tolerance by regulating the expression of target genes at different stages of growth and development. The reversible and specific binding of HSFs to heat shock elements (HSE) led to the activation of transcription (Wang et al., 2017). A potential heat shock factor $H s f 2$ from wheat cv. HD2967 was recognized and cloned. In plants like Arabidopsis and rice the numbers of heat responsive transcription factors so reported are 21 and 25 respectively. When compared to diploid species, the hexaploid genome of wheat is supposed to be the reason of complexity in HSF family structure.

In wheat there must be many unidentified novel HSFs that needs to be characterized. In our results the cloned $H s f 2$ have a conserved HSF -DNA binding domain, high aliphatic index indicating the thermo stability. In leaf there is increase in expression of $H s f 2$ under heat stress in thermotolerant wheat cv. HD2985, HD2967 as compared to HD2329 (thermosusceptible) which signifies the importance of this transcription factor in regulating heat stress tolerance. According to a report of Singh et al. (2019), the high expression of TaHD97 TF gene in leaves of wheat under heat stress at grain filling stage.

Transcript profiling revealed a strong connexion between the expression of HSP90 and Hsf2 under HS. The verdicts in this report are under conformity with the observation of Kumar et al. (2013). The manipulation of $H s f 2$ by genetic approaches could lead to restraining the expression of heat shock proteins (HSPs) and the utilization of this 

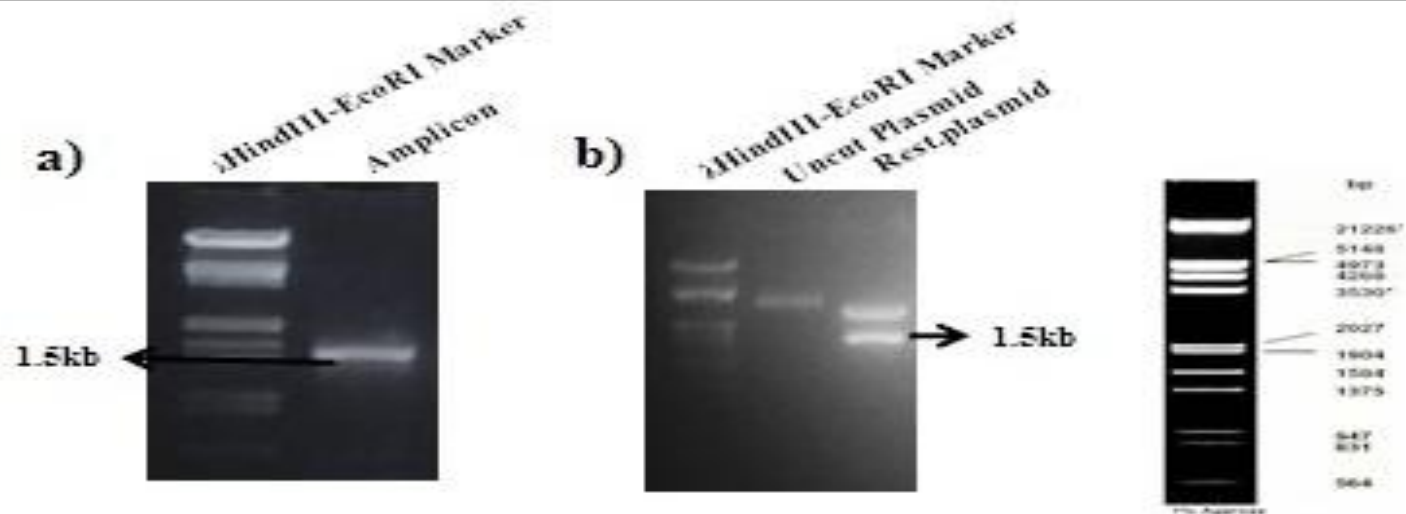

3HindIII-EcoRI Marker

Figure 1a Polymerase chain reaction (PCR) (a) Triticum aestivum gives $\sim 1.5 \mathrm{~kb}$ amplicon with gene-specific primers cloned into pGEMT Easy vector (1b) Restriction of plasmid with EcoRI shows the release of $1.5 \mathrm{~kb}$ insert checked on $1 \%$ agarose gel

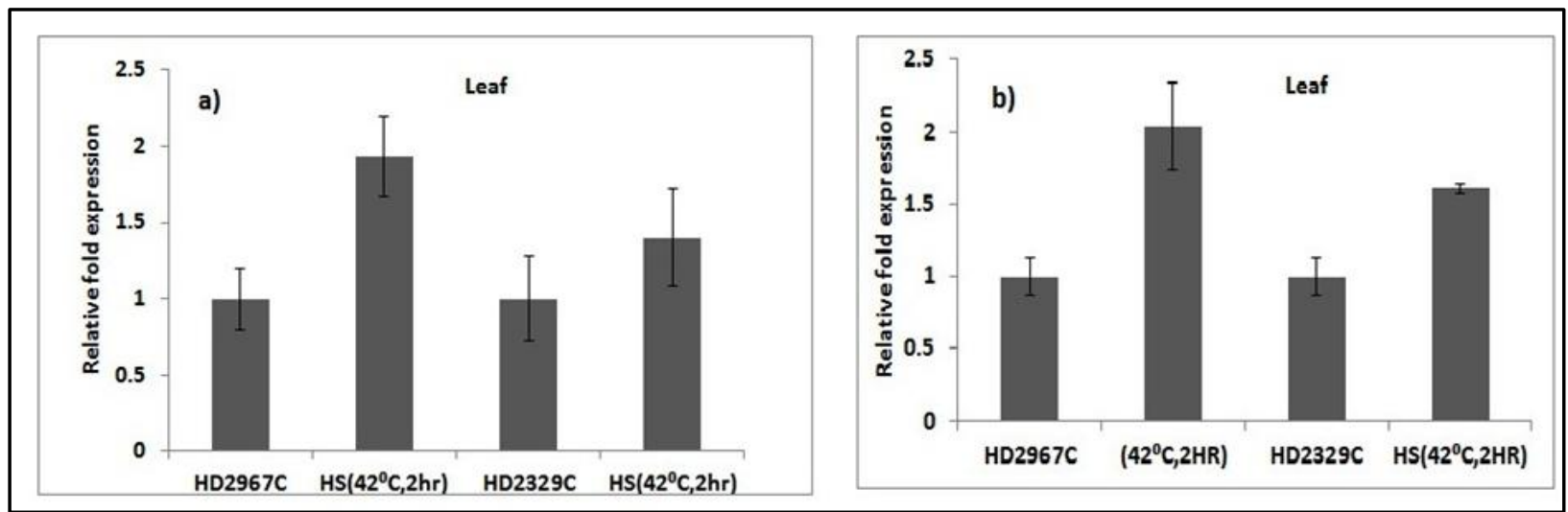

Figure (2a) Verification of putative Hsf2TF gene in wheat (a) Study of Expressions of Hsf2 in leaf of wheat cv. HD2967 and HD2329 at pollination stage (2b) Expression analysis of Hsf2 in leaf of wheat cv. HD2967 and HD2329 at grain filling stage. The $\beta$-Actin gene was used to normalise the data as endogenous control, and the Pfaffl method was used to measure relative fold expression
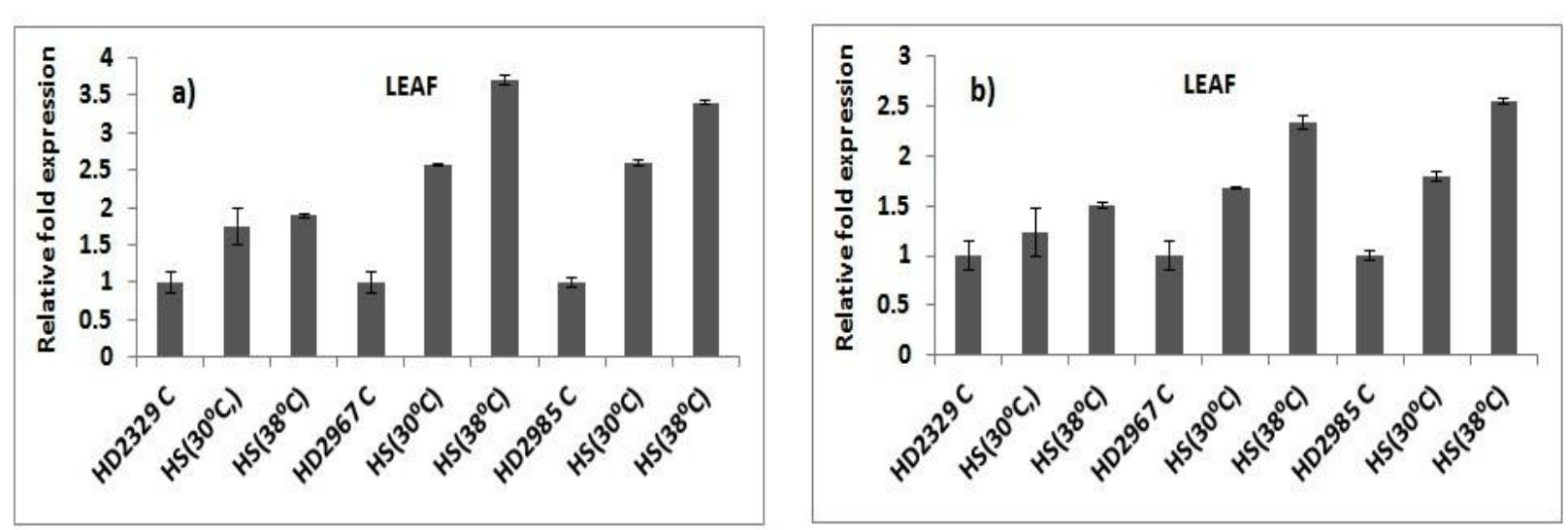

Figure 3(a-b).Expression analysis of target gene (HSP90) of Hsf2 under differential heat stress in three wheat cv. at $30^{\circ} \mathrm{C}$ and $38^{\circ} \mathrm{C}$ for $2 \mathrm{hr}$. (a) Expression analysis of HSP90 in leaf of wheat cv.HD2329, HD2967, HD2985 at pollination stage (b) Expression analysis of HSP90 in leaf of wheat cv.HD2329, HD2967, HD2985 at grain filling stage

Journal of Experimental Biology and Agricultural Sciences http://www.jebas.org 


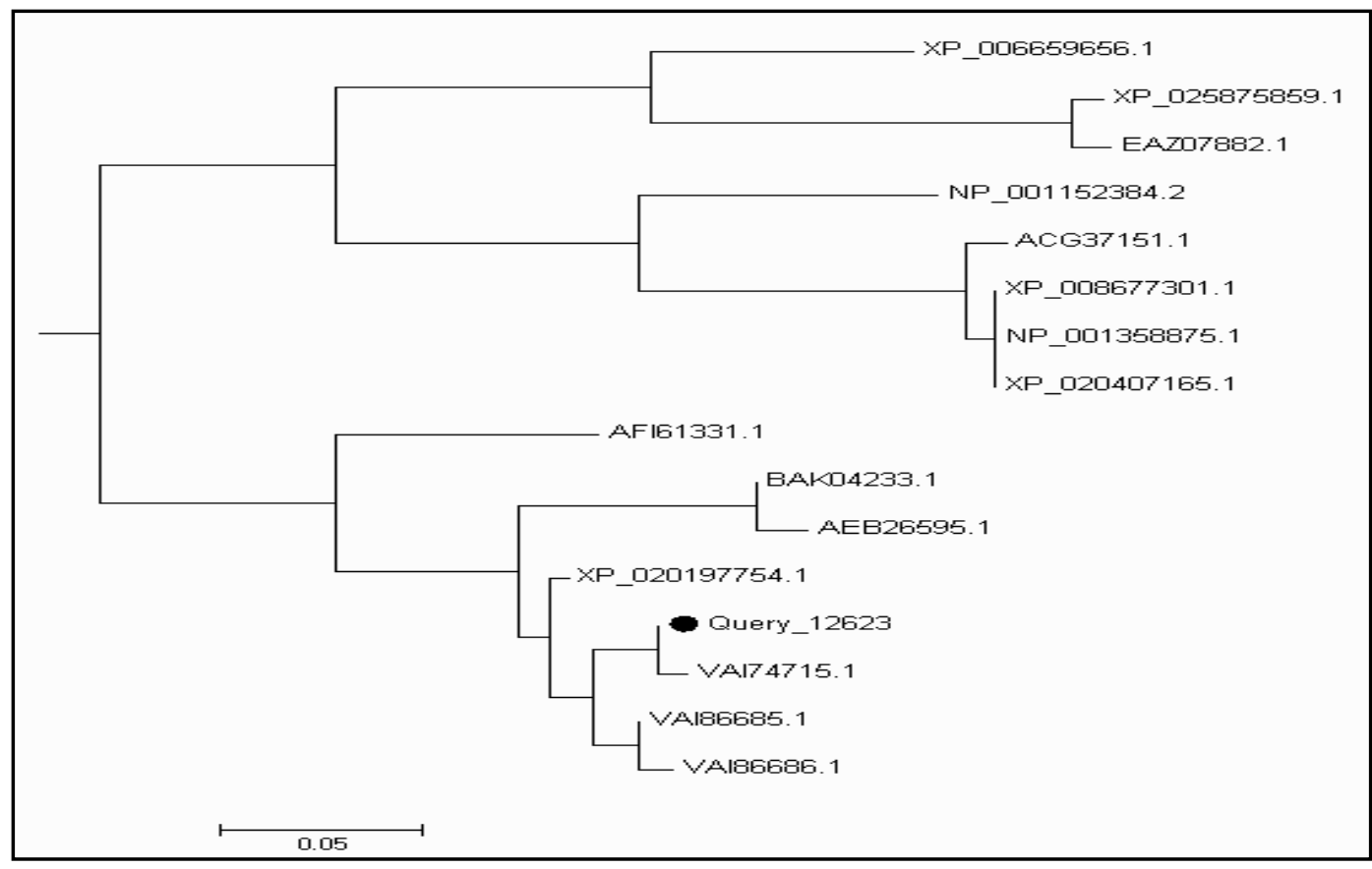

Figure 4 Distance tree of Hsf2 gene (acc.no.KP063542) from Triticum aestivum using NCBI tool

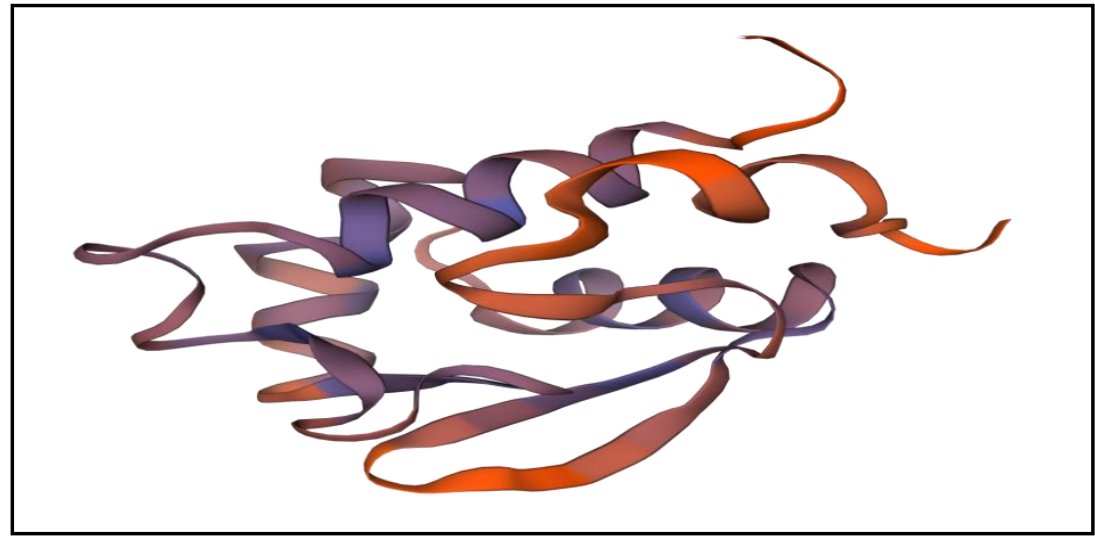

Figure 5 3D modelled structure of Hsf2 from wheat using SWISS-modeller

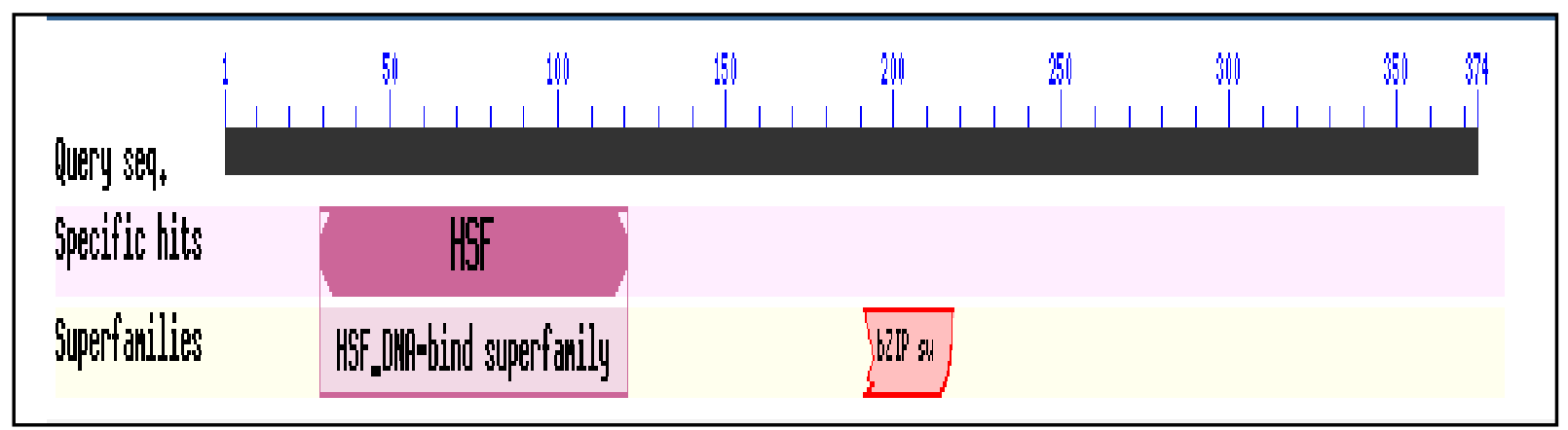

Figure 6 Conserved domain search of $H s f 2$ from wheat using NCBI CD search tool

Journal of Experimental Biology and Agricultural Sciences http://www.jebas.org 


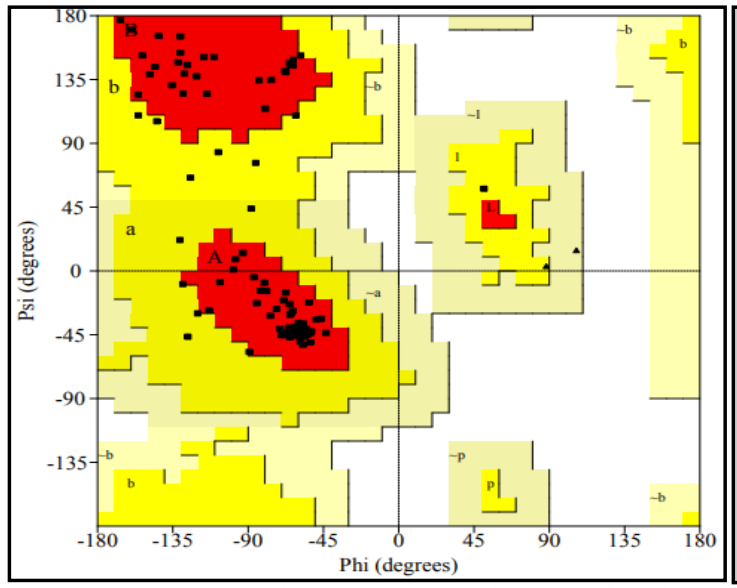

\section{Plot statistics}

Residus in most favoured regions $[\mathrm{A}, \mathrm{B}, \mathrm{L}]$

Residues in additional allowed regions $[a, b, 1, p]$

Revidus in genetrously allowod regions $[-2,-b,-1,-p]$

Residus in disallowed fegions

Number of non-glycine and non-proline residues

Number of end-residues (excl. Gily and Pro)

Number of glycine residues (shown as triangles)

Number of proline residues

Total number of residues

\begin{tabular}{rr}
74 & $86.0 \%$ \\
12 & $14.0 \%$ \\
0 & $0.0 \%$ \\
0 & $0.0 \%$ \\
\hline.. & $10 \%$ \\
\hline 86 & $100.0 \%$ \\
2 & \\
3 & \\
6 & \\
\hline.. & \\
97 &
\end{tabular}

Figure 7 Ramachandran plot of modelled structure of $H s f 2$ protein using PROCHECK server

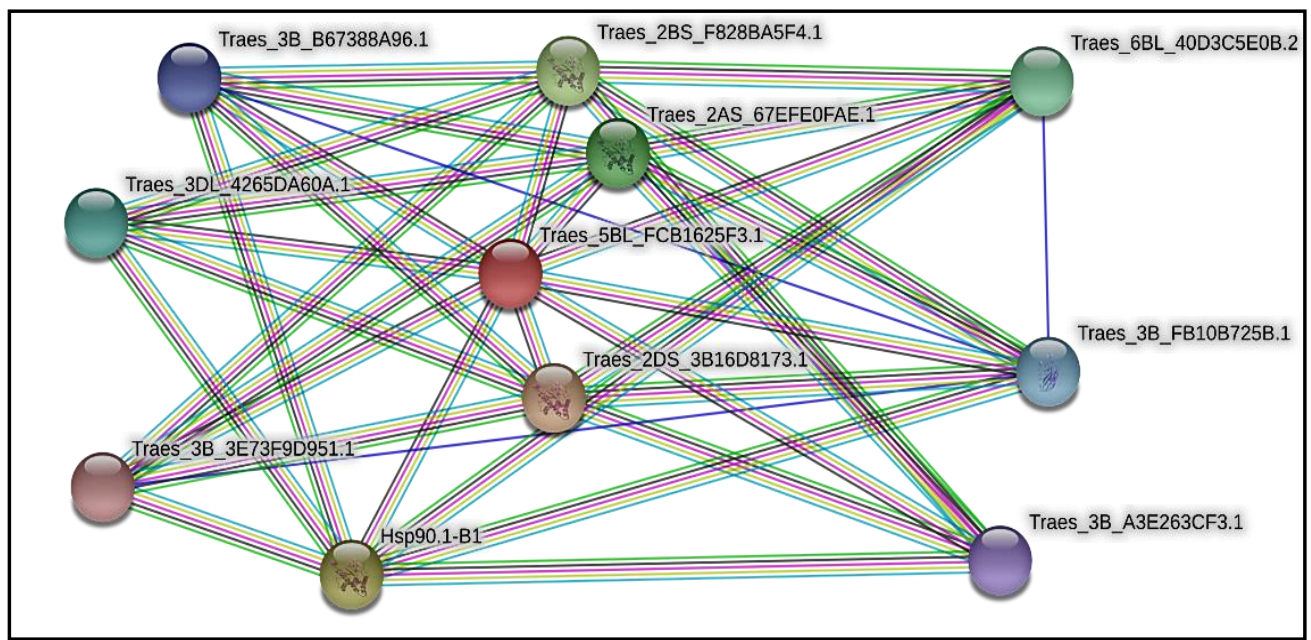

Figure 8 Protein - Protein interaction using STRING Database

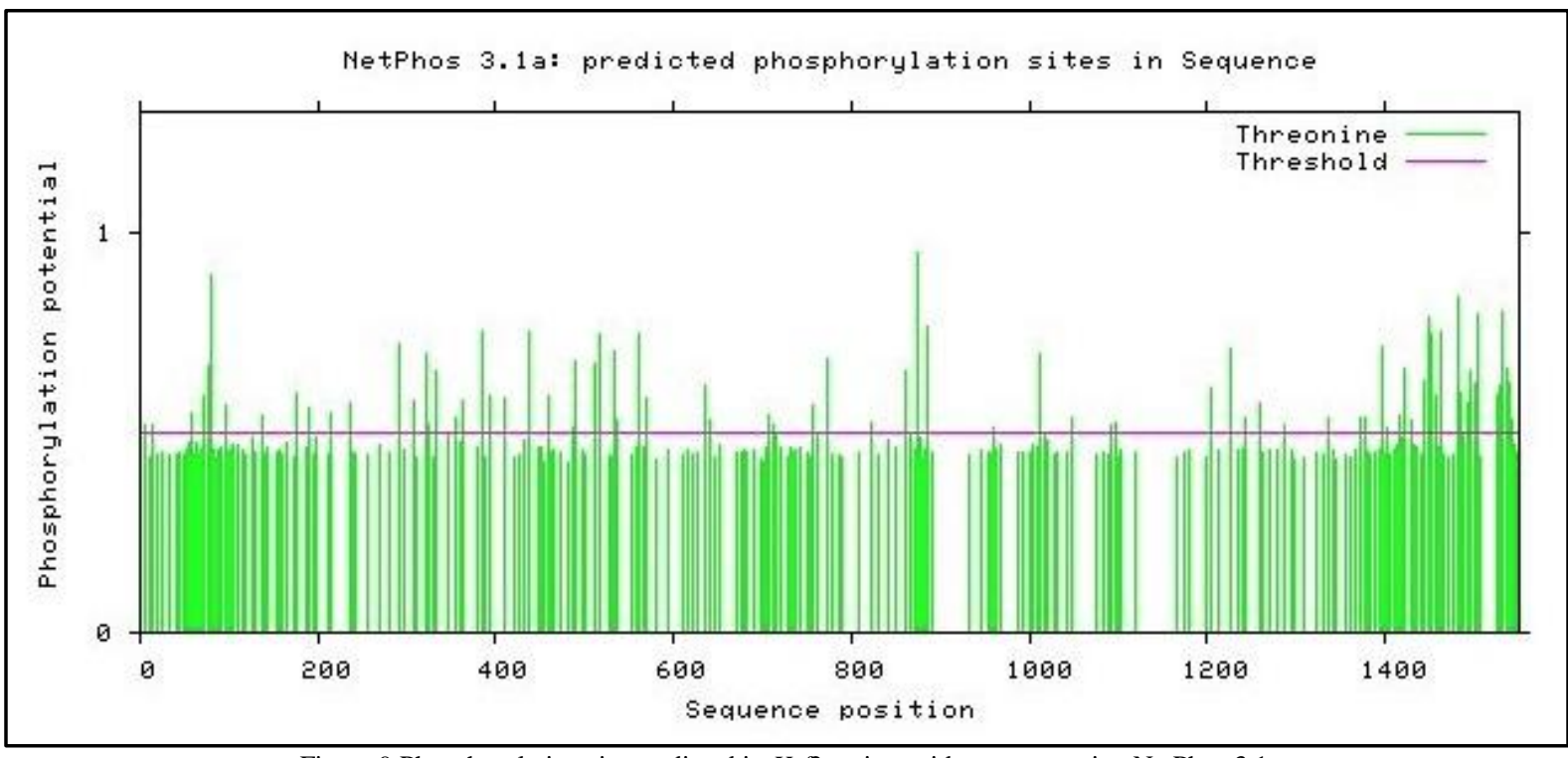

Figure 9 Phosphorylation site predicted in $H s f 2$ amino acid sequence using NetPhos 3.1

Journal of Experimental Biology and Agricultural Sciences http://www.jebas.org 
heat shock factor protein from wheat can help to generate a higher resilient transgenic plant towards thermal stress and hence, provide a mode for an adequate nutrition supply.

\section{Conclusion}

Heat stress is one of the natural phenomena having adverse effects on the productivity of many staple crops especially wheat, Heat shock factors (Hsfs) play a central role in thermotolerance. Here, we cloned a putative heat shock factor $H s f 2$ from Triticum aestivum having potential to regulate the expression of HSP90, a major heat shock protein. The $H s f 2$ transcription factor found in this investigation proves to be one of the main regulating factors of heat stress at different stages of wheat growth and development. The application of this heat shock factor protein from wheat can help to generate a higher resilient transgenic plant towards thermal stress and hence, provide a mode for an adequate nutrition supply.

\section{Acknowledgement}

We, duly acknowledge the grants received from Indian Council of Agricultural Research (ICAR) under National Innovations on Climate Resilient Agriculture (NICRA) project (Sanction no. TG-3079)

\section{Conflict of interest}

The corresponding authors state on behalf of all authors that no conflict of interest exists.

\section{Author Contributions}

RRK, SG planned the research. KD carried out all the experiments and wrote the manuscript. RRK, SG contributed in data analysis. RRK, KD, contributed in gene expression analysis. NK SP contributed in manuscript proofreading. All authors read and approved the manuscript

\section{References}

Aastha V, Lehari K, Burman V, Chauhan C, Singh R, Singh A (2019) Molecular characterization of wheat genotypes using eSSR Markers. Journal of Pharmacognosy and Phytochemistry SP2:1015-1020.

Arnold K, Bordoli L, Kopp J, Schwede T (2006) The SWISSMODEL Workspace: web-based environment for protein structure homology modelling. Bioinformatics 22: 195-201.

Benkert P, Schwede T, Tosatto SCE (2009) QMEAN clust: estimation of protein model quality by combining a composite scoring function with structural density information. BMC Structural Biology 20: 9-35.
Castro M, Peterson CJ, Dalla Rizza M, Dellavalle PD, Vázquez D, Ibanez V, Ross A (2007) Influence of Heat Stress on Wheat Grain Characteristics and Protein Molecular Weight Distribution. In: Buck HT, Nisi JE, Salomón N (Eds.) Wheat Production in Stressed Environments. Developments in Plant Breeding, vol 12. Springer, Dordrecht. https://doi.org/10.1007/1-4020-5497-1_45.

Kills D (2003) Evolution of the cellular stress proteome: From monophyletic origin to ubiquitous function. Journal of Experimental Biology 206: 3119-3124.

Kumar R R, SharmaS K, Goswami S, Singh GP, Singh R (2013) Characterization of differentially expressed stress associated proteins in starch granule development under heat stress in wheat (Triticum aestivum L.). Indian Journal of Biochemistry and Biophysics 50: 126-38.

Kumar RR, Rai RD (2014) Can wheat beat the heat: understanding the mechanism of thermotolerance in wheat (Triticum aestivum L.) a review. Cereal Research Communications 42(1):1-18.

Kumar RR, Tasleem M, Jain M, Ahuja S, Goswami S (2019) Nitric oxide triggered defense network in wheat: Augmenting tolerance and grain-quality related traits under heat-induced oxidative damage. Environmental and Experimental Botany 158: 189-204.

Maestri E, Klueva N, Perrotta C, Gulli M, Nguyen HT, Marmiroli N (2002) Molecular genetics of heat tolerance and heat shock proteins in cereals. Plant Molecular Biology 48 : $667-681$.

Monjardino P, Smith AG, Jones RJ (2005) Heat stress effects on protein accumulation of maize endosperm. Crop Science 45(4):1203-1210.

Nover L, Bharti K, Döring P, Mishra S. K, Ganguli A, Scharf KD (2001) Arabidopsis and the heat stress transcription factor world: how many heat stress transcription factors do we need? Cell Stress Chaperones 6: 177-189.

Pei Q, Yu T, Wu T, Yang Q, Gong K, Zhou R, Cui C, Yu Y, Zhao W, Kang X, Cao R, Song X (2020) Comprehensive Identification and Analyses of the Hsf Gene Family in the Whole-genome of Three Apiaceae Species. Horticultural Plant Journal, DOI: https://doi.org/10.1016/j.hpj.2020.08.005.

Rampino P, Mita G, Pataleo S, Pascali MD, Fonzo ND, Perrotta C (2009) Acquisition of thermotolerance and HSP gene expression in durum wheat (Triticum durum Desf.) cultivars. Environmental Experimental Botany 66: 257-264. 
Rezaei EE, Siebert S, Manderscheid R, Müller J Mahrookashani A, Ehrenpfordt B, Haensch J, Weigel HJ, Ewert F (2018) Quantifying the response of wheat yields to heat stress: The role of the experimental setup. Field Crops Research 217 :93-103.

Rosell CM (2012) Nutritionally enhanced wheat flours and breads. In Breadmaking, Woodhead Publishing, Pp. 687-710 https://doi.org/10.1533/9780857095695.4.687.

Ruelland E, Zachowski A (2010) How plants sense temperature. Environmental and Experimental Botany 61 199-223.

Scharf KD, Berberich T, Ebersberger I, Nover L (2012) The plant heat stress transcription factor (Hsf) family: structure, function and evolution. Biochimica et Biophysica Acta 1819: $104-119$.

Singh JP, Kumar RR, Goswami S, Rai GK, Sakhare A, Kumar S, Singh SD, Bakshi S, Jamhulkar SJ, Sareen S, Singh GP (2019) A putative heat-responsive transcription factor
(TaHD97) and its targets in wheat (Triticum aestivum) providing thermotolerance. Indian Journal of Biotechnology 18: 214-223.

Skylas DJ, Cordwell SJ, Hains PG, Larsen MR, Basseal DJ, Walsh BJ, Blumenthal C, Rathmell W, Copeland L, Wrigley CW (2002) Heat shock of wheat during grain filling: proteins associated with heat-tolerance. Journal of Cereal Science 35(2) :175-188.

Wahid A, Gelani S, Ashraf M, Foolad MR (2007) Heat tolerance in plants: an overview. Environmental and Experimental Botany 61: 199-223.

Wang P, Song H, Li C, Li P, Li A, Guan H, Hou L, Wang X (2017) Genome-wide dissection of the heat shock transcription factor family genes in Arachis. Frontiers in Plant Science 8:106.

Willenborg CJ, Van Acker RC (2008) The biology and ecology of hexaploid wheat (Triticum aestivum L.) and its implications for trait confinement. Canadian Journal of Plant Science 88(5): 997-1013. 